\title{
Gardner Fibroma
}

National Cancer Institute

\section{Source}

National Cancer Institute. Gardner Fibroma. NCI Thesaurus. Code C49017.

An uncommon, poorly circumscribed, benign neoplasm arising in the soft tissues of infants, children and adolescents. It is characterized by the presence of haphazardly arranged spindle-shaped fibroblasts, collag enous stroma formation, and plaque-like growth pattern. There is a strong genetic component associating the neoplasm with Gardners syndrome and deep fibromatosis/desmoid tumor. 